\title{
Student reasoning regarding work, heat, and the first law of thermodynamics in an introductory physics course
}

David E. Meltzer, Department of Physics \& Astronomy, Iowa State University, Ames, IA 50011

Abstract: Written quiz responses of 653 students in three separate courses are analyzed in detail.

There has been relatively little research on student learning of thermodynamics in physics courses at the university level. A recent study by Loverude et al. ${ }^{1}$ has made it evident that students at the introductory level (and beyond) face many significant difficulties in learning fundamental thermodynamic concepts such as the first law of thermodynamics.

I have been engaged in an ongoing project with T. J. Greenbowe to investigate student learning of thermodynamics in both physics and chemistry courses. ${ }^{2}$ As part of that investigation, a short diagnostic quiz has been administered over the past two years in the calculus-based introductory physics course at Iowa State University (ISU). This quiz focuses on heat, work, and the first law of thermodynamics.

At ISU, thermodynamics is studied at the end of the second semester of the twosemester sequence in calculus-based introductory general physics. This course is taught in a traditional manner, with large lecture classes (up to 250 students), weekly recitation sections (about 25 students), and weekly labs taught by graduate students. Homework is assigned and graded every week. Thermal physics comprises $18-20 \%$ of the course coverage, and includes a wide variety of topics such as calorimetry, heat conduction, kinetic theory, laws of thermodynamics, heat engines, entropy, etc.

The diagnostic quiz used in this study is shown below; it has been administered in three separate classes. The version shown here was administered in May 2001; the other two versions (December 1999 and December 2000) had very minor variations from the one shown here. (There were one or two additional questions on these quizzes which are not discussed here.)
The 1999 and 2000 classes were taught by the same instructor, using a different textbook in each course. The 2001 course was taught by a different instructor, using the same text that was employed in the 1999 course. Both instructors are very experienced and have taught introductory physics at ISU for many years.

The quiz was administered in two different ways: in 1999 and 2001, it was given as a practice quiz in the final recitation session (last week of class). In almost all cases it was ungraded; one instructor used it as a graded quiz. In 2000 the quiz was administered as an ungraded practice quiz in the very last lecture class of the year.

This $p$ - $V$ diagram represents a system consisting of a fixed amount of ideal gas that undergoes two different processes in going from state A to state B:

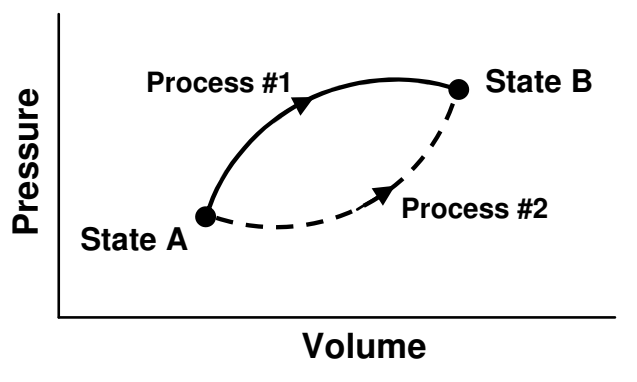

[In these questions, $\boldsymbol{W}$ represents the work done $\boldsymbol{b y}$ the system during a process; $\boldsymbol{Q}$ represents the heat absorbed by the system during a process.]

1. Is $W$ for Process \#1 greater than, less than, or equal to that for Process \#2? Explain.

2. Is $Q$ for Process \#1 greater than, less than, or equal to that for Process \#2? Please explain your answer.

Fig. 1. Thermodynamics diagnostic quiz 


\section{Answers:}

1. $W=\int_{V_{A}}^{V_{B}} p d V=$ the area under the curve in the $p$-V diagram, so $W_{1}>W_{2}$.

2. $\Delta E_{1}=\Delta E_{2} \Rightarrow Q_{1}-W_{1}=Q_{2}-W_{2} \Rightarrow$ $Q_{1}-Q_{2}=W_{1}-W_{2}$. Therefore, $W_{1}>W_{2} \Rightarrow$ $Q_{1}>Q_{2}$. (Since system \#1 loses more energy by doing more work, it must gain more energy through heat absorption to have the same net change in internal energy.)

Correct explanations for \#1 were considered to be virtually anything that mentioned "area under the curve," the integral $\int_{V_{A}}^{V_{B}} p d V$, “working against higher pressure," etc.

A liberal standard was used in assessing answers to \#2; examples of answers considered correct:

" $\Delta E=Q-W$. For the same $\Delta E$, the system with more work done must have more $Q$ input so process \#1 is greater."

" $Q$ is greater for process 1 since $Q=E+W$ and $W$ is greater for process 1."

" $Q$ is greater for process one because it does more work, the energy to do this work comes from the $Q_{\text {in." }}$

An analysis of students' responses on the quiz is shown in Tables I and II.

Table I: Students' reasoning on Work question (*Note: explanations not required in 1999)

\begin{tabular}{lcll}
\hline & $\begin{array}{l}\mathbf{1 9 9 9} \\
(\boldsymbol{n}=\mathbf{1 8 6})\end{array}$ & $\begin{array}{l}\mathbf{2 0 0 0} \\
(\boldsymbol{n}=\mathbf{1 8 8})\end{array}$ & $\begin{array}{l}\mathbf{2 0 0 1} \\
(\boldsymbol{n}=\mathbf{2 7 9})\end{array}$ \\
\hline $\mathbf{W}_{\mathbf{1}}>\mathbf{W}_{\mathbf{2}}$ & $\mathbf{7 3 \%}$ & $\mathbf{7 0 \%}$ & $\mathbf{6 1 \%}$ \\
$\begin{array}{l}\text { Correct or partially } \\
\text { correct explanation }\end{array}$ & $*$ & $56 \%$ & $48 \%$ \\
$\begin{array}{l}\text { Incorrect or missing } \\
\text { explanation }\end{array}$ & $*$ & $14 \%$ & $13 \%$ \\
$\mathbf{W}_{\mathbf{1}}=\mathbf{W}_{\mathbf{2}}$ & $\mathbf{2 5 \%}$ & $\mathbf{2 6 \%}$ & $\mathbf{3 5 \%}$ \\
$\begin{array}{l}\text { Because work is } \\
\text { independent of path }\end{array}$ & $*$ & $14 \%$ & $23 \%$ \\
$\begin{array}{l}\text { Other reason, or } \\
\text { none }\end{array}$ & $*$ & $12 \%$ & $13 \%$ \\
$\mathbf{W}_{\mathbf{1}}<\mathbf{W}_{\mathbf{2}}$ & $\mathbf{2 \%}$ & $\mathbf{4 \%}$ & $\mathbf{4 \%}$ \\
\hline
\end{tabular}

Table II: Students' reasoning on Heat question

\begin{tabular}{llll}
\hline & $\begin{array}{l}\mathbf{1 9 9 9} \\
(\mathbf{n = 1 8 6})\end{array}$ & $\begin{array}{l}\mathbf{2 0 0 0} \\
(\boldsymbol{n}=\mathbf{1 8 8})\end{array}$ & $\begin{array}{l}\mathbf{2 0 0 1} \\
(\boldsymbol{n}=\mathbf{2 7 9})\end{array}$ \\
\hline $\mathbf{Q}_{1}>\mathbf{Q}_{2}$ & $\mathbf{5 6 \%}$ & $\mathbf{4 0 \%}$ & $\mathbf{4 0 \%}$ \\
$\begin{array}{l}\text { Correct or partially } \\
\text { correct explanation }\end{array}$ & $14 \%$ & $10 \%$ & $10 \%$ \\
$\begin{array}{l}\mathrm{Q} \text { is higher because } \\
\text { pressure is higher }\end{array}$ & $12 \%$ & $7 \%$ & $8 \%$ \\
$\begin{array}{l}\text { Other incorrect, or } \\
\text { missing explanation }\end{array}$ & $31 \%$ & $24 \%$ & $29 \%$ \\
$\mathbf{Q}_{\mathbf{1}}=\mathbf{Q}_{\mathbf{2}}$ & $\mathbf{3 1 \%}$ & $\mathbf{4 3 \%}$ & $\mathbf{4 1 \%}$ \\
$\begin{array}{l}\text { Because heat is } \\
\text { independent of path }\end{array}$ & $21 \%$ & $23 \%$ & $20 \%$ \\
$\begin{array}{l}\text { Other explanation, } \\
\text { or none }\end{array}$ & $10 \%$ & $18 \%$ & $20 \%$ \\
$\begin{array}{l}\mathbf{Q}_{\mathbf{1}}<\mathbf{Q}_{\mathbf{2}} \\
\text { Nearly correct, sign } \\
\text { error only }\end{array}$ & $\mathbf{1 3 \%}$ & $\mathbf{1 2 \%}$ & $\mathbf{1 7 \%}$ \\
$\begin{array}{l}\text { Other explanation, or } \\
\text { none }\end{array}$ & $10 \%$ & $8 \%$ & $4 \%$ \\
\begin{tabular}{l} 
No response \\
\hline
\end{tabular} & $\mathbf{0 \%}$ & $\mathbf{4 \%}$ & $\mathbf{3 \%}$ \\
\hline
\end{tabular}

CONCEPTUAL DIFFICULTIES IDENTIFIED IN STUDENTS' RESPONSES

1. Difficulty interpreting work as "area under the curve" on a $p-V$ diagram. Although most students correctly responded that $W_{1}>W_{2}$, only about $50 \%$ of all students were able to give an acceptable explanation. This basic geometrical interpretation is usually the very first topic discussed in connection with $p-V$ diagrams, and it is difficult to make efficient use of such diagrams without understanding this idea.

2. Belief that work done is independent of process. A substantial number (15-25\%) of students are under the impression that work is (or behaves as) a state function, and that the work done during a process depends only on the initial and final states. Many students state this very explicitly in their written explanations. Others do not have such a clearly expressed notion, but still identify the work done by the two processes in the diagram as being equal to each other. 
3. Belief that heat absorbed is independent of process. About $20-25 \%$ of all students explicitly state a belief that the heat absorbed during a process depends only on the initial and final states. (Answers categorized as "Because heat is independent of path" include those stating that both processes reached the same final state, had the same initial and final states, etc.) In addition, the claim that $Q_{1}=Q_{2}$ was justified by a wide variety of other explanations.

4. Association of greater heat absorption with higher pressure. The most popular alternative explanation for $Q_{1}>Q_{2}$ was that higher pressures were involved in Process \#1. It was clear, though, that students were not considering the process as a whole (omitting, e.g., any consideration of initial and final states), and were simply associating "heat" with "pressure," often through appeals to the ideal gas law.

5. Use of a "compensation" argument, e.g., "more work implies less heat," etc. A significant number of students attempted to employ an argument that states, roughly speaking, "more heat (or work) implies less work (or heat)." For instance, only 5\% of students who claimed $W_{1}=W_{2}$ also argued that $Q_{1}<Q_{2}$; however, that argument was made by $20 \%$ of students who had correctly answered $W_{l}>W_{2}$. In some cases, it was clear that students were employing the first law of thermodynamics in the form $\Delta E=Q$ $+W$ (i.e., $W$ being defined as work done on the system). This was not the convention used in their physics class, although it is typically the one used in chemistry courses. An analogous argument was used by other students who explicitly employed $\Delta E=Q-$ $W$; these students were often making a simple sign error (and are categorized as "Nearly correct, sign error only" in Table II). The "compensation" argument was also seen in the explanations of the (very few) students who stated that $W_{1}<W_{2}$; most of them went on to argue that $Q_{1}>Q_{2}$.
6. Inability to make use of the first law of thermodynamics. Even including students who made sign errors (as described above), only about $15 \%$ of all 653 students were able to give a correct answer with a correct explanation based on the first law of thermodynamics. There was almost no variation in this proportion from one class to the next, despite changes in instructors and textbooks.

\section{CLUES REGARDING CONCEPTUAL DYNAMICS}

Among the most interesting and important aspects of students' reasoning (from the instructor's standpoint) is the path along which learning takes place. ${ }^{3}$ By this I mean the sequences of ideas that lead either to productive or unproductive lines of thought from the standpoint of yielding good learning outcomes. In the present case we have an observation of student thinking at only a single point in time. Therefore, any hypotheses we induce from the data must be tested through sequential observations and student interviews. Nonetheless, there are several provocative aspects of the data that are consistent over all the observations.

\section{A. Patterns underlying students' responses}

1. Although a belief in pathindependence of heat is somewhat more common among students who answer $W_{1}$ $=W_{2}$, more than one third of those who correctly answer $W_{1}>W_{2}$ also claim that $Q_{1}=Q_{2}$. About half of the students who answer $W_{1}=W_{2}$ also state that $Q_{1}=Q_{2}$ (1999: 40\%; 2000: 51\%; 2001: 53\%). However, a very substantial number of those who realize that work is dependent on process (and correctly answer $W_{l}>W_{2}$ ) also seem to believe that heat is not process dependent. This is implied by the fact that more than one third of those who answer $W_{1}>W_{2}$ also claim that $Q_{1}=Q_{2}$ : 1999: 29\%; 2000: 41\%; 2001: 34\%. This somewhat unexpected result is made more provocative by the following observation. 
2. Students are more likely to justify a $Q_{1}=Q_{2}$ answer by explicitly asserting that " $Q$ is path-independent" if they answered the Work question correctly. Students who answered the Work question incorrectly and who also stated $Q_{1}=Q_{2}$ often gave no explanation for their answer to the Heat question. Only infrequently did they claim that heat was "independent of process" or use words to that effect (e.g., "both processes ended at the same point," "had the same initial and final points," etc.). By contrast, students who answered the Work question correctly but stated that $Q_{1}=$ $Q_{2}$ usually did explicitly claim that heat was independent of process. (See Tables III, IV.)

\begin{tabular}{lcc}
\hline Table III. Students who answer $Q_{1}=Q_{2}(2000)$ \\
\hline $\mathbf{2 0 0 0}$ & $\begin{array}{l}\text { Correct } \\
\text { on work } \\
\text { question } \\
(\boldsymbol{n}=\mathbf{5 4})\end{array}$ & $\begin{array}{l}\text { Incorrect } \\
\text { on work } \\
\text { question } \\
(\boldsymbol{n}=\mathbf{2 7})\end{array}$ \\
\hline $\begin{array}{l}\text { Explain by claiming } \\
\text { "heat is independent of } \\
\text { path" }\end{array}$ & $61 \%$ & $36 \%$ \\
\hline $\begin{array}{l}\text { Explain with other } \\
\text { reasons, or no } \\
\text { explanation given }\end{array}$ & $39 \%$ & $63 \%$ \\
\hline
\end{tabular}

\begin{tabular}{lcc}
\multicolumn{3}{l}{ Table IV. Students who answer $Q_{l}=Q_{2}(2001)$} \\
\hline $\mathbf{2 0 0 1}$ & $\begin{array}{l}\text { Correct } \\
\text { on work } \\
\text { question } \\
(\boldsymbol{n}=\mathbf{5 8})\end{array}$ & $\begin{array}{l}\text { Incorrect } \\
\text { on work } \\
\text { question } \\
(\boldsymbol{n}=\mathbf{5 5})\end{array}$ \\
\hline $\begin{array}{l}\text { Explain by claiming } \\
\text { "heat is independent of } \\
\text { path" }\end{array}$ & $66 \%$ & $35 \%$ \\
\hline $\begin{array}{l}\text { Explain with other } \\
\text { reasons, or no } \\
\text { explanation given }\end{array}$ & $34 \%$ & $65 \%$ \\
\hline
\end{tabular}

\section{B. Conjectures on conceptual dynamics}

1. Belief that heat is processindependent may not be strongly affected by realization that work is not processindependent. The process-dependence of both heat and work are fundamental concepts in thermodynamics. Because the formalism of $p$ - $V$ diagrams is ubiquitous in physics instruction, a very natural representation of the idea of process dependence is that different paths, representing different processes, are characterized by different amounts of work done ("areas under the curve"). It might seem then that the process-dependence of work should be easier to grasp, at least at the formal level, than that of heat. One might think that when a student gains this perception about work, the idea of heat also being dependent on process would not be such a big leap. The data suggest that the linkage between these concepts in instruction may not be as close as one might guess.

2. Understanding the processdependence of work may strengthen belief that heat is independent of process. Various interpretations of the data in Tables III and IV are possible. For instance, students who have a good grasp on the concept that "work is area under the curve" may also have a clearer perception than do other students that something, at least, is independent of process in thermodynamics. If they have not yet clearly grasped the idea of internal energy change, they may too readily transfer that perception, mistakenly, to heat. On the other hand, these data may simply reflect a better ability to express their (incorrect) ideas on the part of students who correctly answer the Work question.

This material is based upon work supported by the National Science Foundation under Grant Number DUE-9981140.

\section{REFERENCES}

1. M.E. Loverude, P.R.L. Heron, and C.H. Kautz, "Student understanding of the first law of thermodynamics: Relating work to the adiabatic compression of an ideal gas," Phys. Educ. Res., Am. J. Phys. Suppl. (to be published).

2. D.E. Meltzer and T.J. Greenbowe, "Recurrent areas of confusion in student learning of thermodynamics," AAPT Announcer 31(2), 81 (2001).

3. R.K. Thornton, "Conceptual Dynamics: following changing student views of force and motion," in AIP Conf. Proc. 399, E.F. Redish and J.S. Rigden, eds. (AIP, N.Y., 1997), pp. 241-266. 